\title{
The Impact of Internal Marketing on Internal Service Quality: A Case Study in a Jordanian Pharmaceutical Company
}

\author{
Amjad Abu ELSamen ${ }^{1} \&$ Muhammad Alshurideh $^{1}$ \\ ${ }^{1}$ Faculty of Business, Marketing Department, The University of Jordan, Amman, Jordan \\ Correspondence: Muhammad Alshurideh, Faculty of Business, Marketing Department, The University of Jordan, \\ Amman, Jordan. E-mail: m.alshurideh@ju.edu.jo
}

Received: May 6, 2012 Accepted: August 29, 2012 Online Published: October 1, 2012

doi:10.5539/ijbm.v7n19p84 URL: http://dx.doi.org/10.5539/ijbm.v7n19p84

\begin{abstract}
The purpose of this research is to examine the impact of Internal Marketing (IM) on the Perceived Internal Service Quality (ISQ). Data was collected from 225 employees working in a Jordanian Pharmaceutical company. Our results indicated that that there is a positive relationship between Internal Marketing dimensions and perceived Internal Service Quality in varying magnitude. Further, our investigation showed that the dominant dimension of IM was found to be Recruitment with the stronger impact on all perceived internal service. Service providers are recommended to apply IM strategy in order to enhance perceived ISQ foster better external service quality.
\end{abstract}

Keywords: internal marketing, internal service quality, Jordan, Middle East, pharmaceutical

\section{Introduction}

The concept of Internal Marketing (IM) is a relatively new approach that has been investigated by researchers and adopted by companies in order to enhance the quality of their products and services and to achieve a better performance. Today, businesses have found it indispensable to look inward and asses their operations internally and most importantly they found that it is crucial to understand their human resources views about the company. A change in mindset has emerged through research that is conducted in this area where companies is regarding their employees as customers that must be served and the quality of this service is important to ensure the success of the business. In this research we aim to investigate the implications of internal marketing on internal service quality at a Jordanian Pharmaceuticals company. In this research, we examine the relationships among the seven internal marketing practices and the delivered internal service quality. Hence, we assess the efficiency of the tools and methods used in marketing the company internally to their employees, thus, allowing them to know their employees views and how they perceive the treatment they receive on their everyday work, this will grant managers the ability to find areas which needs improvement for further analysis if needed to ensure the high productivity of their employees.

\subsection{Research question and aims}

This research intends to answer the following research question: What are the impacts of Internal Marketing (IM) on Internal Service Quality at a Jordanian Pharmaceuticals company. ? Based on the research question and the research model that drawn below, two objectives have been planned to be studied as:

1) Examining the effect of internal marketing dimensions (employee motivation and reward, effective communication, employee recruitment, employee selection, employment development, support system and healthy work environment) on the Internal Service Quality.

2) Determine the importance of each of the internal marketing dimensions in explaining the variation in internal service quality.

\subsection{Literature Review}

\subsubsection{The Concept of Internal Marketing}

The notion of the Internal Marketing appeared in 1970's; it has been founded to solve the problems that occur due to the lack of delivering services in a high quality (Panigyrakis, 2009), so the companies should work hard to improve a method which improves the delivery of services, Drake (2005) concluded that the company should 
make its employees love its brand which will convince the customer to love it as well. Furthermore, Vasconcelos (2007) argued that the external marketing strategies will be improved firstly by improving the internal marketing strategy such as developing the internal relationships between the internal customers (the employees), also by satisfying the need for the internal customers and services providers to make them satisfied and motivated (Tsai \& Tang, 2008). Berry (1984) described IM as "viewing employees as internal customers, viewing jobs as internal products, and then endeavoring to offer internal products that satisfy the needs and wants of these internal customers while addressing the objectives of the organization". Also, IM has been seen as "service firms' effort to provide all members of the organization with a clear understanding of the corporate mission and objectives and with the training, motivation, and evaluation to achieve the desired objectives. Some scholars have seen the IM as a process. For example, Ballantyne et al. (1995) mentioned that" IM is considered to be the process of creating market conditions within the organization to ensure that internal customers' wants and needs are met". Furthermore, some scholars have focused on the organizations" employees and see them as core stone or assets that should be motivated to execute properly the business when discussing the IM discipline. George and Gronroos (1989) defined IM as" Internal market of employees is best motivated for service-mindedness and customer-oriented behaviors by an active, marketing-like approach, where marketing-like activities are used internally'. Also, Kotler \& Amstrong (1991) defined IM as" the building of customer orientation among employees by training and motivating both customers-contact and support staff to work as a team". So the company should think how to sell the internal products to the internal customers to fulfill the company objectives and deliver services in a high quality. Accordingly, recognition has appeared to highlight the importance of the IM and its relationship with improving the service delivery and how it affects the external marketing strategy, and also how to keep the internal workforces satisfied and motivated. Roberts Lombard pointed that "The successful application of the principles of internal marketing on the internal market of the business is a prerequisite for effective external marketing" (Herington et al. 2006 cited Lombard, 2010 p.371). Based on above explanation, this study adapts the main IM dimensions that has been developed and employed in the previous literature as will be explained in the next section.

\subsubsection{Motivation and Reward System}

Companies that seek competitive advantage through employees must be able to manage the behavior and results of all employees. One of the most difficult challenges is how to get managers to distinguish between good, average, and poor performers (Noe, Hollenbeck, Gerhart, \& Wright, 2006). Benefiting from employees' knowledge requires a management style that focuses on developing and empowering employees to held accountable for products and services; in return, they share the rewards and losses of the results. Pay plan are typically used to energize, direct, or control employee behavior. Most employees compare their own pay with that of others, especially those in the same job. (Noe, Hollenbeck, Gerhart, \& Wright, 2006). Many organizations today recognize that motivating employees also requires a level of respect between management and workers. This respect can be seen as involving employees in decisions that affect them, listening to employees, and implementing their suggestions where appropriate. (Decenzo \& Robbins, 2005, page 43). Tansey \& McGrath, (2004) addressed the manner in which management can use internal marketing to motivate employee to provide the best possible service to customers. The study focused on using the internal marketing as a mechanism for ensuring the motivation of service employees. The implementation of an internal marketing program ensures that motivation is at the forefront of managements' priorities. Papasolomou (2006) have indicated that there is no doubt that the motivation is an important factor which improves the performance of the employees; many companies set a systematic reward system to motivate its employees to improve their service quality and delivery. Every person is unique and has a motivational key which makes this person work harder and give more. Motivation may come from financial and non-financial elements. Financial and non-financial motivation must be developed to employees according to their job levels, such as paying them bonuses and commissions, or educational development of job trainings and courses (Roberts-Lombard, 2010). The most important issue is how to communicate the motivation programs within the organization. An effective way to create trust and commitment between the employees and their managements is building team sessions. Managements must arrange regular meetings with the employees to listen to their needs, enquiries, complains and recommendations, to address the needs of each employee on an individual basis (Roberts-Lombard, 2010). Based on above explanation, the hypothesis is drawn as follow:

H1: There is a positive relationship between employee motivation and reward and perceived Internal Service Quality. 


\subsubsection{Effective Communication}

Internal communication is defined as "all forms of communication from management to employees in service organization" (Lovelock, 1999, p.248). Organizations must give a serious consideration to improve the level of communication with employees to communicate its vision and missions and provide effective strategies to transfer knowledge and information, by using different methods such as team work discussion sessions and internal newsletters (Roberts-Lombard, 2010). An effective internal communication is very important tool for the internal marketing, it helps the management to ensure service delivery with high satisfactory level and build employee trust, respect and loyalty (Lovelock, 1999, p.248). Based on above explanation, the hypothesis is drawn as follow

H2: There is a positive relationship between effective communication and perceived Internal Service Quality.

\subsubsection{Effective Employee's Selection}

Selection is described by Khan et al. (2010) as a systematic process of choosing the right candidates with the right qualifications to handle the requirements of a job vacancy or future job openings. Khan et al. (2010, p.4) argued that "Selection is the major and first factor which plays a key role in the quality services". Hence it is how managers can match the characteristics of the selected employees to the job description and job requirements because if the management fails in doing that, the company will suffer with these employees (DeCenzo/Robbins, $10^{\text {th }}$ edition). On the other hand, if the management selection depends on relating the characteristics to the required job skills, ability, descriptions and needs it will help the employees and organization to work effectively (Burke \& Wilcox, 1969). Based on above explanation, we hypothesis:

H3: There is a positive relationship between effective employee selection and perceived Internal Service Quality.

\subsubsection{Effective Recruitment}

Recruitment is defined by Tuchtfeldt $(1998$, p.2) as "practice of soliciting and actively seeking applicants to fill recently vacated or newly created positions using a variety of methods". Recruitment criteria should reflect both the human dimensions and technical requirements of the job, many candidates help the organization to choose better employees and the diversity also enable creating a wide pool of employees that will allow the organization to think effectively before choosing one from the candidates, this will effectively help in creating an effective process of recruitment which helps the organization to work better and effective (Tuchtfeldt, 2007). Based on above explanation, the hypothesis is drawn as follow:

H4: There is a positive relationship between effective employee recruitment and perceived Internal Service Quality.

\subsubsection{Effective Development}

Employees should be developed and trained to know the required tasks to do their job well which work with the organizations objectives to get the job well done (Piercy, 1991). Also empowerment is an effective part of employee development (Proctor \& Doukakis, 2003), empowerment means authorizing and enabling employees to act, behave, think and make their decision to get the job faster and easy to make (Kaner et al., 2007). This depends on enablement of the employees and giving them the resources they need to use their own discretion confidently and effectively to take new responsibility (Lovelock, 1999). This support getting the job faster in the organization and creates experience in different levels in the organization (Gronroos, 1981). Furthermore, employees choose various career paths, according to Michael Driver \& Brousseau (1980) not everyone is suited to navigating careers oriented toward power and wealth, they also identified four different paths that people's careers generally take and these are: first, Linear career path: employee rise in an organization until they reach the pinnacle of hierarchy. Second, steady state experts: these employees are motivated to achieve a high level of expertise in a particular area. Third, spirals: employees that are motivated by learning and personal growth. Finally, transistorizes: these are motivated by variety and novelty. Companies must undertake strategies that ensure their employees concepts and how they view their career path can be achieved by considering the kinds of strategies that, if successful, logically could be expected to create organizational conditions supportive of each career concept" (Driver \& Brousseau, 1997). Based on above explanation, the hypothesis is drawn as follow:

H5: There is a positive relationship between effective employment development and perceived Internal Service Quality. 


\subsubsection{Effective Support System}

Technology plays a big role in developing organization's performance and making the internal processes faster; Pugh et al. (2002) argued that providing support systems such as information system facilitate the service delivery. Furthermore, Pride (2000) said that the main role of a marketing system is how to retrieve and save data at the required time, using new technologies such as the internet, VOIP, Mobile phones and video conferences help the employees and teams to interact regionally and to break the boundaries between the organization branches to act inter-functionally, inter-functionality means how the organization is effective in transforming strategies, knowledge, information, and abilities within the organization without barriers and how to integrate them together to accomplish the organization strategies and objectives (McAfee, 1992). This will help the organizations to work more efficiently and effectively. Based on above explanation, the hypothesis is drawn as follow:

H6: There is a positive relationship between effective support system and perceived Internal Service Quality.

\subsubsection{Healthy Work Environment}

It is not easy to create a healthy working environment, organizations should evaluate the current situation of the healthy environment and try to change the required aspects to have a healthy environment such as: stop smoking in the internal offices and departments, keep the dangerous materials away from the employees, create awareness about the safety requirements and programs and keep the places clean (DeCenzo/Robbins, $10^{\text {th }}$ edition). Based on above explanation, the hypothesis is drawn as follow:

H7: There is a positive relationship between healthy work environment and perceived Internal Service Quality

\subsubsection{Internal Service Quality (ISQ)}

A careful reviewing of the literature about Internal Service Quality (SQ) over the last two decades indicates that SQ has been the subject of interest for many studies. Jain and Gupta (2004, p.25) mentioned that "Quality has come to be recognized as a strategic tool for attaining operational efficiency and improved business performance". According to Zeithaml \& Bitner, 1996 (cited Yusoff \& Baharun, 2008, p.6), internal customer was defined as "any member (employee) of the organization receiving service and product from other members of the organization to carry out his or her job". This means that meeting the requirements exactly as customers needs is the quality means for many organizations. Thus, internal service is defined as the service provided between different organizational departments (Kang et al, 2002). According to Opoku et al (2009), internal marketing is strongly related to the perceptions of internal service quality. Furthermore, their results suggested that "employees who use and are satisfied with the services offered have higher perceptions of the interaction quality". In the reviewed literature about the internal service marketing, researchers argued that providing a better service to the internal customers (Internal Service Quality) will lead to a higher quality service provided to external customers (External Service Quality)(Bouranta et al., 2005). Several instruments have been developed to measure the service quality such as SERVQUAL, and SERVPERF. The SERVQUAL instrument has been the predominant method used to measure customer's perception of service quality. Reynoso \& Moore (1995) were the first to attempt to utilize the SERVQUAL instrument as a measure of the Internal Service Quality, and justified the transferability of this instrument from external to internal customers. Since there is no general agreement on a specific measurement tool for the internal service quality concept, most of the studies have used the SERVQUAL methodology to measure it. Kang et al. (2002) concluded that the SERVQUAL items can be modified to measure the employees' perceptions of internal service quality and assess the quality of internal service provided to employees of different departments within the same organization. SERVQUAL is a multi-item instrument established by Parasuraman et al. $(1985 ; 1988)$ it measures the consumer's perceptions of service quality. 


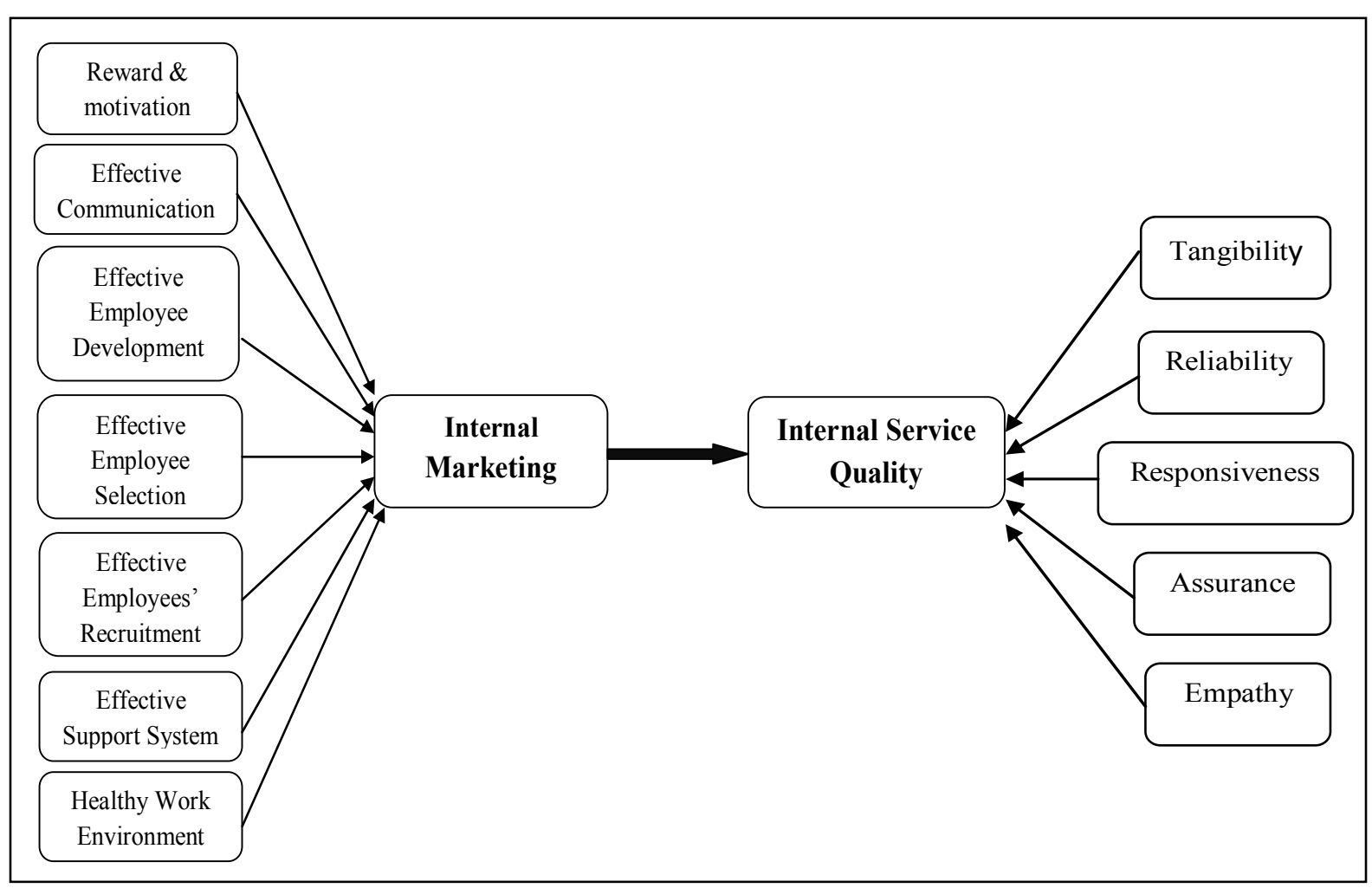

Figure 1. Proposed research model: interrelation among Internal Marketing (IM) and Internal Service Quality (ISQ)

In figure 1 as shown below, there are many ISQ tool which mainly contains five generic dimensions as explained mainly by Lovelock (1999) and other scholars (e.g. Reynoso \& Moores, 1995; Asubonteng et al., 1996; Kang et al., 2002) which are: 1) Tangibles: which relates to what do the service provider's Physical facilities; equipment, personnel, and communication look like, and how the service providers offer modern equipment, comfortable working environment and professional appearance. 2) Reliability: which is related to what the company providing services as promised dependably and accurately, and how coworkers can handle problems, provide right information, be reliable and provide promised service. 3) Responsiveness: which explain how the employees are willing to help customers and provide prompt service? In this, how coworkers are helpful, answer any question, and help in any request and how much the communication is clear and accurate.4) Assurance: which shows how the employees are helpful and knowledgeable, polite and trustworthy? This indicates to what level the coworkers are polite, trustful and knowledgeable with each others. 5) Empathy: which shows how do employees give individualized concerns between each others? Coworkers have each other's best interest, give the employee attention, understand work related needs and to what extent the working hours are comfortable and convenient. The following part discusses the relationship between internal marketing elements on service quality.

\subsubsection{Internal Marketing (IM) and Internal Service Quality (ISQ)}

According to Berry (1994) the human Resource practices such as selection, recruitment, and other practices are very important factors that play a key role in the quality of service, this is how companies compete in this respect to improve the internal quality of service, by training, developing, selecting and recruiting the human capabilities in the organization. Relating the candidate capabilities with the required job skills will help the organization to improve the business performance and internal interaction between the employees. Furthermore, training employees for specific purposes like how to communicate with others will help in improving the internal service quality among the coworkers. Also, motivation helps in supporting employees and encourages them to work hard and accept the training and development programs to improve their capabilities to ensure developing their skills, and to understand the required work environment and surrounded circumstances, on the other hand, these practices will also help in understanding the need of information technology and how to use it which helps in improving the quality of internal service by implementing a support system. Implementing a 
support system and information technology will facilitate the communication between the managers and employees and employees between each other through various communication means (e.g outlook, Emails, video conference .etc), the support system breaks the barriers between department which makes the information flow faster and more accurately which means the internal service quality is improving.

\section{Research Methodology}

Data was collected using a survey based method. The questionnaire was developed based on the internal marketing and service quality literature. The questionnaire were personally delivered to 250 employees working in X company, of which 225 were usable for analysis. The studied sample was constituted by $64.4 \%$ males and $35.6 \%$ females. $43 \%$ of the respondents were between 25-29 years old. Majority of the respondents were holding bachelor degrees representing $83 \%$ while $14.7 \%$ were of the master degree holders. Half of the sample (51\%) with work experience ranging between $3-5$ years, and $25 \%$ with $5-10$ years of experience. The questionnaire which has been used in this research consists of closed-ended questions and scale questions. It starts with 6 demographic information (gender (G), age (A), educational level (E), and years of experience (Y), level of employment (L) and the department (D); the questionnaire was designed to indicate the degree of acceptance of respondents regarding the effect of internal marketing aspects on Internal Service Quality. A 7 point Likert scale of extremity ranging from 1, 'strongly disagree' to 7, 'Strongly Agree' was used to answer the questions. Measurement instrument with the Cronbach alpha coefficient for each dimension is shown in table 1 below.

\section{Data Analysis}

First of all, because we are relying on single rater, common method variance (CMV) maybe of an issue. In this research, The Harman's single factor test was conducted to diagnose common method variance. This method loads all items from each of the constructs into an exploratory factor analysis to see whether one single factor does emerge or whether one general factor does account for a majority of the covariance between the measures. The unrotated factor solution results in a multiple factors model, rather than a one-factor model, that explains the majority of the covariance among the measures. Hence, CMV is not a pervasive issue.

Cronbach alpha was calculated for each scale to test the reliability and the degree to which the items are tapping the same concept. Results show that Cronbach's alpha for the eight-item scale of motivation and reward system (RM) is 0.693 , for the five-item scale of effective communication (C) is 0.727 , for the four-item scale of employee development (D) is 0.631 , for the three-item scale of support system (SS) is 0.747 , for the four-item scale of employee selection (ES) is 0.591 , for the four-item employee recruitment scale (ER) is 0.671 , and for the four-item scale of healthy work environment (WE) is 0.615 . Moreover, Cronbach's alpha for the Internal Service Quality main items were calculated as shown in table number 2 below and the results were as follow: tangibility scale $(\mathrm{T})$ is 0.738 , for the three-item reliability scale $(\mathrm{R})$ is 0.615 , for the five-item responsiveness scale (RS) is 0.809 , for the four-item assurance scale (A) is 0.787 , and for the four-item empathy scale (E) was 0.704. It is noticeable that the Cronbach alpha value were between 0.60 and 0.80 . some may argue that these value are below the threshold values. However, we believe that a moderate value of Cronbach alpha is essential because it indicates that the items are not identical and that the measures are capturing more of the constructs domains.

Table 1. Internal Marketing (IM) reliability measurements
Rewards and Motivation (IMRM)-Cronbach alpha $=0.693$
IMRM1: Understanding the meaning of motivation.
IMRM2: Understanding the importance of motivation.
IMRM3: The Company is aware about the need of motivation.
IMRM4: The Company is aware about positive effects of motivation.
IMRM5: I know the measurement methods of my performance.
IMRM6: Reward is systematic according to the job evaluation
IMRM7: Reward is greater than punishment.
IMRM8: I know how I get reward 
Communication (IMC )- Cronbach alpha $=0.727$

IMC1: Information is easy to get within the Company.

IMC2: Management arranges regular meetings to listen to the employees.

IMC3: Job description is clearly understood.

IMC4: Management encourages team working.

IMC5: Vision, Mission and Organizational goals are clearly understood.

Development (IMD) - Cronbach alpha $=0.631$

IMD1: The Company applies training programs to enhance your current skills and develop new ones.

IMD2: Clearly identified career path.

IMD3: Satisfaction of the contribution in design making at your level.

IMD4: Enabling resources required to full-fill the job effectively.

Support System(IMSS)-Cronbach alpha $=0.747$

IMSS1: Using helpful methods and equipment to communicate and interact such as (Internet \& Video conferences)

IMSS2: Using data base to help in retrieving saving information.

IMSS3: Availability of IT department to provide technology support (creating, fixing, devolving soft wares).

Employee Selection (IMES)-Cronbach alpha $=0.591$

IMES1: The company has a vision to define upcoming human resources need in the upcoming future.

IMES2: The company is willing to have an extra number of candidates and keep them as backup for any future requirements.

IMES3: Qualified, well-educated and innovative employees have a priority to work at Hikma Pharmaceuticals.

IMES4: Company matches job requirements with the employee skills.

Employee Recruitment (IMER)-Cronbach alpha $=0.671$

IMER1: The selection system is based on justice \& quality

IMER2: The company utilizes multiple resources to attract the right employees (e.g. advertising in newspaper)

IMER3: The company uses defined measurement tool to evaluate the candidate's capabilities and skills.

IMER4: The company provides a Special team to assess the candidate before interviewing them.

Healthy Work environment (WK)-Cronbach alpha $=0.615$

IMER1: The company has a safe working environment.

IMER2: The company adapts adequate safety programs

IMER3: Dangerous materials are kept in a separate place.

IMER4: Safety instructions are followed during the work 
Table 2. Internal Service Quality (ISQ) reliability measurements

\begin{tabular}{l} 
Construct 2: Internal Service Quality (ISQ) \\
\hline Tangibility (ISQT)-Cronbach alpha $=0.738$ \\
ISQT1: The company has Up-to date equipments and instruments. \\
ISQT2: The company facilities are clean and visually appealing. \\
ISQT3: The employees look neat and professional appearance. \\
ISQT4: The Working environment is comfortable and happy \\
ISQT5: The Materials used to provide the service are visually appealing \\
ISQT6: The parking place is adequate compared with employees' number.
\end{tabular}

$$
\text { Reliability(ISQRL)-Cronbach alpha }=0.615
$$

ISQRL1: Coworkers provide the service that is promised.

ISQRL2: Coworkers perform the service right the first time, to avoid later correction.

ISQRL3: Coworkers are reliable to provide the correct information.

$$
\text { Responsiveness(ISQRS)-Cronbach alpha }=0.809
$$

ISQRS1: Coworkers are sincerely interest about any problem and in solving it.

ISQRS2: Coworkers are willing to help each other.

ISQRS3: Coworkers respond quickly and efficiently to my requests.

ISQRS4: Communication between employees is clear, accurate and appropriate.

ISQRS5: Coworkers are capable to accommodate special work requirements and needs when requested.

$$
\text { Assurance(ISQA)-Cronbach alpha }=0.787
$$

ISQA1: Trust and honest exist between coworkers and employees.

ISQA2: Colleagues are polite, kind, and respectful.

ISQA3: Safety and security when dealing with coworkers

ISQA4: Colleagues have good knowledge and skills.

$$
\text { Empathy(ISQE)-Cronbach alpha }=0.704
$$

ISQE1: The working hours are convenient

ISQE2: Coworkers have each other's best interest in mind.

ISQE3: Coworkers give me individual attention and concern.

ISQE4: Coworkers understand my work related needs.

Hypotheses were tested using multiple regression analysis. The first phase, summated scale for each of the main constructs dimensions was calculated. Where as in phase two, five multiple regression tests were conducted and the hypotheses were examined as follow:

\subsection{IM dimensions and ISQ Tangibility}

The test findings indicate there is a significant positive relationship between IM dimensions and perceived ISQ Tangibility. As can been in table 3,36.9\% of the variation in perceived ISQ tangibility is explained by IM. Three factors of IM were found to significantly affecting tangibility: Employees Motivation $(\beta=0.362$, significant at 0.000$)$, Support System $(\beta=0.323$, significant at 0.000$)$ and Recruitment $(\beta=0.146$, significant at 0.022). Mean while, communication, employee development, employee selection, and work environment failed to show significant relationships with perceived ISQ tangibility.

\subsection{IM and ISQ Reliability}

The test findings indicate there is a significant positive relationship between IM dimensions and perceived ISQ Reliability. As can be seen in table $3,28.7 \%$ of the variation in perceived ISQ Reliability is explained by IM. Three factors of IM were found to significantly affecting reliability: Recruitment ( $\beta=0.234$, significant at 0.001 ), 
Support System $(\beta=0.154$, significant at 0.016$)$ and Development $(\beta=0.154$, significant at 0.042$)$ are the strongest predictors of variations in the perceived ISQ Reliability, respectively. Mean while, motivation, communication, employee selection, and work environment failed to show significant relationships with perceived ISQ Reliability.

\subsection{IM and ISQ Responsiveness}

The test findings indicate there is a significant positive relationship between IM dimensions and perceived ISQ Responsiveness. As can be seen in table 3,33.9\% of the variation in perceived ISQ Responsiveness is explained by IM. Three factors of IM were found to significantly affecting responsiveness: Support System $(\beta=0.262$, significant at 0.000 ), Recruitment ( $\beta=0.234$, significant at 0.000 ) and Motivation $(\beta=0.204$, significant at 0.001 ) are the strongest predictors of variations in the perceived ISQ Responsiveness, respectively. Mean while, Communication, Employee Development, employee selection, and work environment failed to show significant relationships with perceived ISQ Responsiveness.

\subsection{IM and Assurance}

The test findings indicate there is a significant positive relationship between IM dimensions and perceived ISQ Assurance. As can be seen in table 3,33.6\% of the variation in perceived ISQ Assurance is explained by IM. Three factors were found to significantly affecting assurance: Support System $(\beta=0.276$, significant at 0.000$)$, Motivation ( $\beta=0.239$, significant at 0.000$)$ and Recruitment $(\beta=0.129$, significant at 0.049$)$ are the strongest predictors of variations in the perceived ISQ Assurance, respectively. Mean while, Communication, Employee Development, employee selection, and work environment failed to show significant relationships with perceived ISQ Assurance.

\subsection{IM and Empathy}

The test findings indicate there is a significant positive relationship between IM dimensions and perceived ISQ Empathy. As can be seen in table 3,31.1\% of the variation in perceived ISQ Empathy is explained by IM. Three factors were found to significantly affecting empathy: Recruitment $(\beta=0.205$, significant at 0.002$)$, Development ( $\beta=0.192$, significant at 0.010 ) and Selection (standardized $\beta=0.136$, significant at 0.046 ) are the strongest predictors of variations in the perceived ISQ Empathy, respectively. Mean while, Motivation, Communication, work environment and support system failed to show significant relationships with perceived ISQ Empathy.

Table 3. The effect of im dimensions on each of the isq dimensions

\begin{tabular}{|c|c|c|c|c|c|c|c|c|c|c|}
\hline \multirow[t]{2}{*}{ IM Dimension } & \multicolumn{2}{|c|}{ Tangibility } & \multicolumn{2}{|c|}{ Reliability } & \multicolumn{2}{|c|}{ Responsiveness } & \multicolumn{2}{|c|}{ Assurance } & \multicolumn{2}{|c|}{ Empathy } \\
\hline & $\begin{array}{c}\text { Std } \\
\text { B }\end{array}$ & $\begin{array}{c}\text { T-Valu } \\
\text { e }\end{array}$ & Std B & $\begin{array}{c}\text { T-Valu } \\
\text { e }\end{array}$ & Std B & $\begin{array}{c}\text { T-Valu } \\
\text { e }\end{array}$ & Std B & T-Value & Std B & T-Value \\
\hline Motivation & .362 & 5.904 & .128 & 1.958 & .204 & 3.252 & .239 & 3.801 & .082 & 1.277 \\
\hline $\begin{array}{l}\text { Communicatio } \\
\mathrm{n}\end{array}$ & -.072 & -.596 & .099 & .777 & .079 & .638 & .061 & .495 & .134 & 1.070 \\
\hline Development & .081 & 1.153 & .154 & 2.049 & .086 & 1.182 & .127 & 1.756 & .192 & 2.596 \\
\hline Selection & -.012 & -.185 & -.020 & -.289 & -.071 & -1.061 & .091 & 1.362 & .136 & 2.010 \\
\hline Recruitment & .146 & 2.299 & .234 & 3.462 & .234 & 3.599 & .129 & 1.981 & .205 & 3.086 \\
\hline $\begin{array}{l}\text { Work } \\
\text { Environment }\end{array}$ & .067 & .524 & .087 & .633 & .120 & .903 & -.013 & -.095 & .008 & .063 \\
\hline $\begin{array}{l}\text { Support } \\
\text { System }\end{array}$ & .323 & 5.370 & .154 & 2.420 & .262 & 4.260 & .276 & 4.493 & .110 & 1.754 \\
\hline
\end{tabular}

Tangibility $=4.267+(0.320)$ Motivation $+(0.508)$ Support System $+(0.215)$ Recruitment

Reliability $=2.018+(0.166)$ Recruitment $+(0.117)$ Support System $+(0.113)$ Development

Responsiveness $=0.057+(0.385)$ Support System $+(0.323)$ Recruitment $+(0.168)$ Motivation

Assurance $=0.839+(0.314)$ Support System $+(0.152)$ Motivation $+(0.137)$ Recruitment

Empathy $=1.385+(0.204)$ Recruitment $+(0.198)$ Development $+(0.141)$ Selection 


\section{Results Discussion}

With a confidence level of $95 \%$, and according to the results mentioned in the data analysis section, the significant IM predictors were positively influencing the five variables of the perceived ISQ, and their correlations are explained as follow:

\subsection{Motivation Was the Most Significant Variable Influencing Tangibility}

Motivated employees tend to have better perception of the ISQ. There is no doubt that the motivation is an important factor which improves the performance of the employee and improves their service quality and delivery.

\subsection{Recruitment Was the Most Significant Variable Influencing Reliability}

This can be achieved by enhancing the recruitment process, which will increase the candidate pool for the top management to select the right employees with the required skills that fits the job requirements, which will enhance the reliability between coworkers in performing the right and promised services, as well as providing correct information without the need for afterward corrections.

\subsection{Support System Was the Most Significant Variable Influencing Employees Responsiveness}

Using a well developed support system and new technologies will improve the level of responsiveness between coworkers in solving problems, helping each other, responding quickly and efficiently to any request, deliver accurate communication, and accommodate special work requirements and needs.

\subsection{Support System Was the Most Significant Variable Influencing Assurance among employees}

Using the Support system available in the company such as emails, cell phones and database (REP system) by employees can help increasing the assurance between them through dealing by formal correspondences with more processional, respectful manner and honesty.

\subsection{Recruitment Was the Most Significant Variable Influencing Empathy among Employees}

Effective recruitment process will increase the probability of hiring the suitable candidates to create a team environment with harmony and high empathy level. Based on above results, a conclusion can be drawn that the proposed hypotheses are supported and the overall internal service quality will be improved if internal marketing dimensions were applied well in the company. According to the table (4) below, the hierarchal ranking of the significant IM on ISQ variables, recruitment was founded to be the common factor, followed by the support system, Employee motivation, effective development and effective employee selection respectively.

Table 4. IM and ISQ dimensions hierarchal ranking (1: high, 2: medium, 3: low)

\begin{tabular}{cccccc}
\hline ISQ & Motivation & Recruitment & Development & Support System & Selection \\
\hline Tangibility & 1 & 3 & & 2 & \\
Reliability & & 1 & 3 & 2 & \\
Responsiveness & 3 & 2 & & 1 & \\
Assurance & 2 & 3 & & & 3 \\
Empathy & & 1 & 2 & & \\
\hline
\end{tabular}

\section{Conclusion and Recommendations}

The purpose of this study was to examine the impacts of Internal Marketing (IM) on perceived Internal Service Quality at a Jordanian Pharmaceutical company. Although there is a large amount of literature on internal marketing but still there is limited empirical evidence on its impact on the perception of internal service quality generally (Grönroos, C1994) and specifically in the Jordanian market. Research results showed that recruitment, support system, motivation, development and selection were respectively the strongest predictors affecting perceived ISQ. Recruitment was the common predictor on all ISQ dimensions. Contacting the employees, we were informed that they are not fully aware of the recruitment procedures and strategies but during the last five months the company started to apply a systemized recruitment procedure in which they distribute an internal posting of any job vacancy directly for all the employees clarifying the needed requirements and qualifications. So that, a close advice is to monitor and develop a new motivation system applications and performance support tools to enhance the internal work environment (Schaffer S \& Overcast, 2001). 
As for the support system, the major respondents were from the sales department, upon further investigation, we found out that this department was using support system called CRM (Customer Relationship Management) which has been stopped for more than one year as they are trying to get an upgraded version. While other departments such as purchasing, operations, HR, finance, business development, IT and medical affairs are using other support system called SAP (System Applications and Products). This might be able to contribute to the low perception of the support system in our sample.

As a result, top management is encouraged to motivate their employees by implementing a reward system such as bonuses and incentives, in addition to high quality training courses and continued education scholarships. Furthermore, we recommend conducting regular meetings more frequently to explore the employees' needs and problems. There are some other important managerial implications from this study which suggest that top management should be engaged more in implementing the concept of internal marketing and to focus their attention to apply it sufficiently in different departments to make it more familiar among their employees. Moreover, internal service quality should be established as a long-term goal for the company. The means and the methods to achieve it should also be defined and resources should be devoted to it. Based on the above discussion, results can be concluded by supporting the hypotheses that there are positive relationships between the following: employee motivation and reward, effective employee recruitment, effective employee selection, effective employment development, effective support system and perceived Internal Service Quality. While the other hypotheses were not supported which are: The relationship between effective communication and healthy work environment dimensions and perceived Internal Service Quality.

Some limitations exist throughout this study that must be identified. These limitations include the accessibility to all company departments-Employee's misunderstanding about the importance of the questionnaires. We worked hard to avoid the level of the limitations and tried to touch the real situation of the company to get real answers that support this study. Finally, further research is suggested to investigate the factors of IM that lead to establish high perceived ISQ of successful relationships with internal customers in order to have improved external service quality are suggested to investigate.

\section{Acknowledgements}

I acknowledge this work to all our colleagues who help in reviewing this manuscript and providing us with their insightful comments.

\section{References}

Asif Khan, M., Mehmood, Q., \& Ur-Rehman, I. (2010). Perceived internal services quality in human resources management and its impacts on employee job satisfaction. 1-7. Retrieved from http://www.iqraisb.edu.pk/icbte-old1/Proceeding_ICBTE_2010/Proceeding\%20Papers/120.pdf

Asubonteng, P., McCleary, K., \& Swan, J. (1996). SERVQUAL revisited: a critical review of service quality, Journal of Services Marketing, 10(6), pp.62-81. http://dx.doi.org/10.1108/08876049610148602

Ballantyne, D., Christopher, M., \& Payne, A. (1995). Improving the quality of services marketing: Service (Re) design is the critical link. Journal of Marketing Management, 11(1-3), 7-24. http://dx.doi.org/10.1080/0267257X.1995.9964326

Berry, L. (1984). Service Marketing is different. In Kang, G-D., Jame, J., Alexandris, K. (2002). Measurement of internal service quality: application of the SERVQUAL battery to internal service quality, Managing Service Quality, 12(5), 278 - 291.

Burke, R., \& Wilcox, D. (1969). Characteristics of effective employee performance review and development interviews. Personnel Psychology, 22(3), 291-305. http://dx.doi.org/10.1111/j.1744-6570.1969.tb00334.x

DeCenzo D., \& Robbins, S. (2005). Fundamentals of human resource management ( $8^{\text {th }}$ edition). John Wiley and Sons.

Drakes, S. M., Gulman, M.J., \& Roberts, S. M.(2005). Light their Fire. Dearborn, Chicago.

Driver, \& Brousseau, $\quad$ (1997). Retrieved from http://www.ruttenbergconsulting.com/newsletters/Career\%20Paths\%20-\%20July\%202010.pdf

Herington et al. (2006). Internal Relationships-Linking practitioner literature and relationship marketing theory in Lombard, M. (2010). Employees as customers-An internal marketing study of the Avis car rental group in South Africa, African Journal of Business Management, 4(4), 362-372.

Johnson, E. M., Scheuing, E. E., \& Gaida, K. A. (1986). Profitable Service Marketing. Dow-Jones, Irwin, 
Homewood, IL.

George, W. R., \& Gronroos, C. (1989). Developing-customer conscious employee at every level-Internal Marketing. In Kang, G-D., Jame, J., Alexandris, K. (2002) Measurement of internal service quality: application of the SERVQUAL battery to internal service quality, Managing Service Quality, 12(5), 278-291.

Grönroos, Ch. (1994). From Marketing Mix to Relationship Marketing: Towards a Paradigm Shift in Marketing. Management Decision, 32(2), 4-20. http://dx.doi.org/10.1108/00251749410054774

Jain S., \& Gupta G. (2004). Measuring Service Quality: SERVQUAL vs. SERVPERF Scales. vikalpa, 29(2), 25-37.

Kaner, S., Lind, L., Toldi, C., \& Berger, C. (2007). Facilitator's Guide to Participatory Decision-Making, Jossey Bass, San Fransisco, USA.

Kang, G-D., J Jame, J., \& Alexandris, O. (2002). Measurement of internal service quality: application of the servqual battery to internal service quality. Managing Service Quality, 12(5), 278-291. http://dx.doi.org/10.1108/09604520210442065

Kotler, P., \& Armstrong, G. (1991). Principles of Marketing, Prentice-Hall. Upper Saddle River, NJ

Liao, H., Toya, K., Lepak, D., \& Hong, Y. (2009). Do They See Eye to Eye? Management and Employee Perspectives of High-Performance Work Systems and Influence Processes on Service Quality. Journal of Applied Psychology, 94(2), 371-391. http://dx.doi.org/10.1037/a0013504

Lovelock C., \& Wright L. (1999). Principles of marketing management, New York, USA.

Mishra, S. (2010). Internal Marketing A Tool to Harness Employees' Power in Service Organizations in India. International Journal of Business Management, 5(1), 185-193.

Noe, R. Hollenbeck, J. Gerhart, B, \& Wright, P. (2006). Human Resource Management ( $5^{\text {th }}$ edition). McGraw-Hill.

Opoku, R., Atuobi-Yiadom, N., Chong, C., \& Abratt R. (2009). The impact of internal marketing on the perception of service quality in retail banking: A Ghanaian case. Journal of Financial Services Marketing, 13(4), 317-329. http://dx.doi.org/10.1057/fsm.2008.26

Panigyrakis, G., \& Theodoridis, P. (2009). Internal Marketing Impact on Business Performance in a Retail Context. International Journal Retail and distribution management, 37(7), 600-628. http://dx.doi.org/10.1108/09590550910964620

Proctor, T., \& Doukakis, I. (2003). Change management: the role of internal communication and employee development. Corporate Communications: An International Journal, 8(4), 268-277. http://dx.doi.org/10.1108/13563280310506430

Roberts-Lombard, M. (2010). Employees as customers - An internal marketing study of the Avis car rental group in South Africa. African Journal of Business Management, 4(4), 362-372.

Rafiq M., \& Ahmed P. (2000). Advances in the internal marketing concept: definition, synthesis and extension. Journal of services marketing, 14(6), 449-462. http://dx.doi.org/10.1108/08876040010347589

Reynoso, J., \& Moores, B. (1995). Towards the measurement of internal service quality. International Journal of Service Industry Management, 6(3), 64-83. http://dx.doi.org/10.1108/09564239510091349

Schaffer, S., \& Overcast, Sh. (2001). Learning system design considerations in creating an online learning environment. Performance Improvement, 40(9), 38-45. http://dx.doi.org/10.1002/pfi.4140400908

Tansey, L., McHugh, E., \& McGrath, E. (2004). The Role of Internal Marketing in the Motivation of High Contact Service Employees. Retrieved from http://www.kai.mahnert.de/studybuddy.doc

Tsaia Y., \& Tang Ta-Wei. (2008). How to improve service quality: Internal marketing as a determining Factor. Total Quality Management, 19(11), 1117-1126. http://dx.doi.org/10.1080/14783360802323479

Tuchtfeldt S. (2007). Human Resource Management, Ideology and Gender: An explorative approach to recruiting practices and the special case of executive search firms. Norderstedt, Germany.

Yusoff, A., \& Baharun, R. (2007). Internal customer orientation in a Malaysian telecommunications company. International Business Academics Consortium, 1-17. Retrieved from hattp://ibacnet.org/bai2007/proceedings/Papers/2007bai7687.doc 